-Full Paper-

\title{
Isolation and Culture of Rabbit Primordial Germ Cells
}

\author{
Ryo KAKEGAWA ${ }^{1)}$, Takeshi TERAMURA ${ }^{2,3)}$, Toshiyuki TAKEHARA ${ }^{1)}$, Masayuki ANZAI ${ }^{4}$, \\ Tasuku MITANI ${ }^{4}$, Kazuya MATSUMOTO' ${ }^{1}$, Kazuhiro SAEKI ${ }^{1)}$, Norimasa SAGAWA ${ }^{2)}$, \\ Kanji FUKUDA ${ }^{3,5)}$ and Yoshihiko HOSOI')
}

\begin{abstract}
${ }^{1)}$ Graduate School of Biology-Oriented Science and Technology, Kinki University, Wakayama 649-6493, ${ }^{2)}$ Department of Obstetrics and Gynecology, Graduate School of Medicine, Mie University, Mie 514-8507, 3) Institute of Advanced Clinical Medicine, Kinki University School of Medicine, Osaka 589-8511, ${ }^{4)}$ Institute of Advanced Technology, Kinki University, Wakayama 642-0017 and ${ }^{5)}$ Department of Orthopaedic Surgery, Kinki University School of Medicine, Osaka 589-8511, Japan
\end{abstract}

\begin{abstract}
Primordial germ cells (PGCs) are embryonic precursors of the gametes of adult animals and are considered stem cells of the germline. Since their proliferation in vitro correlates well with the schedule of developmental changes in vivo, they might be interesting research tools for genomic imprinting, germ-cell tumors and fertility. Furthermore, once primordial germ cells are separated and placed on a feeder layer with cytokines, they become cultured pluripotent cell lines called embryonic germ (EG) cells. EG cells share several important characteristics with embryonic stem (ES) cells as they can also contribute to the germ line of chimeras. To investigate the characteristics of PGCs and establish rabbit EG (rEG) cells, we cultured rabbit PGCs (rPGCs) in vitro with various combinations of leukemia inhibitory factor (LIF), basic fibroblast growth factor (bFGF) and forskolin on inactivated mouse embryonic fibroblast (MEF) feeder layers. The present study found PGC proliferation in early cultures and induction of rEG-like colonies. These cells expressed pluripotent markers, such as alkaline phosphatase activity, OCT-4, Sox-2 and SSEA-1, in the undifferentiated state; however, the cells did not develop into a teratoma when injected into the kidney capsules of SCID mice, although the restricted differentiation potentials to neural cells were determined via embryoid body formation. From these characteristics and further characterization of the germ stem cell markers Vasa, SCP-1 and SCP-3, we suggested that these were hybrid cells with characteristics somewhere between PGC and EG cells.
\end{abstract}

Key words: Differentiation, Embryonic germ cells (EG cells), Pluripotency, Primordial germ cells (PGCs), Rabbit

(J. Reprod. Dev. 54: 352-357, 2008)

$\mathbf{P}$

GCs are embryonic cells that migrate through the genital ridge, where they ultimately give rise to gametes. PGCs carry forward the phenotype of each individual, including all of its defects, into future generations, and characterization and detailed description of their germ cell differentiation will lead to better understanding of fertility, childhood diseases, germ-cell tumors and methods of contraception.

In mice, primitive germ cells were first identified at embryonic day 6.25 in the most proximal layer of the epiblast [1] and were observed throughout PGC migration from somatic tissues by expression of tissue non-specific alkaline phosphatase (TNAP) activity [2]. During migration, PGCs actively proliferate and increase in number by about 300-fold until initiation of sex differentiation of the fetal gonads [3-5]. Then, PGCs mitotically arrest or enter the first meiotic division to form a gamete [6]. Interestingly, they also show a limited period of proliferation in vitro and enter growth arrest, which correlates well with their developmental changes in vivo [7]. Furthermore, when isolated mouse PGCs were cultured, electron microscopy and enzymatic analyses indicated that a large proportion of the PGCs died as a result of apoptosis, probably because some fetal germ cells die as a result of apoptosis during migration and differentiation in the developing fetal gonad

Accepted for publication: June 13, 2008

Published online in J-STAGE: July 16, 2008

Correspondence: Y. Hosoi (e-mail: hosoi@waka.kindai.ac.jp)
$[8,9]$. To maintain the PGCs in culture, supplementation of growth factors is essential. Treatment with leukemia inhibitory factor (LIF) and stem cell factor (SCF) increases the survival of mouse PGCs by reducing apoptosis $[10,11]$.

In the presence of multiple growth signals, PGCs can restart rapid proliferation and sometimes transform into pluripotent EG cells $[12,13]$. EG cells share several important characteristics with ES cells, including their morphology, cell surface markers such as stage-specific embryonic antigen-1 (SSEA-1) and transcription factors such as Oct-4 [5, 12]. More importantly, EG cells can also contribute to the germ line of chimeras when injected into blastocysts [14].

Because of their potential use for gene manipulation, isolation of EG cells in various species might give rise to numerous agricultural and biomedical applications; however, establishment of EG cells in species other than mice [12] and humans [15] has proven difficult.

In the present study, we collected PGCs from rabbit fetuses at various embryonic stages and cultured them under various conditions. Furthermore, we characterized pluripotent cell markers of the cultured cells.

\section{Materials and Methods}

\section{Collection of rPGCs}

The embryo donors were New Zealand White female rabbits 
(approximately 6 months of age) crossbred with males of the same strain. The animals were sacrificed on Day 8 to 11 of gestation, and embryos were dissected from the uteri. The genital ridges were dissected from the embryos, and the dorsal mesentery was removed. The isolated tissues were washed once with PBS and incubated in $0.04 \%$ (w/v) Trypsin- $0.25 \%$ (w/v) EDTA solution (Sigma-Aldrich, St. Louis, MO, USA) for $5 \mathrm{~min}$ at room temperature. After incubation, the PGCs were dissociated by gentle disruption of the tissues using a glass capillary tube.

These animal experiments were conducted in accordance with the Guidelines of Kinki University for the Care and Use of Laboratory animals.

\section{Culture of rPGCs in various culture conditions}

The 9.5 day post coitum (dpc) embryos were sacrificed in order to determine suitable PGC culture conditions. The dissociated cells were washed and cultured on mitotically inactivated MEF feeder layers in PGC culture medium composed of knockout DMEM (Invitrogen, Carlsbad, CA, USA), Knockout SR (Invitrogen) at final concentration 20\% (v/v) L-glutamine, sodium pyruvate, MEM nonessential amino acids and 2-mercaptoethanol. The PGC culture medium was supplemented with or without leukemia inhibitory factor (LIF) at 1,000 IU/ml (ESGRO; Chemicon International, Temecula, CA, USA) and recombinant basic FGF (bFGF; Upstate, Charlottesville, VA, USA) at 0, 10, 20 or $30 \mathrm{ng} / \mathrm{mL}$. Furthermore, the effect of forskolin (Sigma-Aldrich) was also examined by adding it at 0,20 or $40 \mu \mathrm{M}$ to PGC culture medium containing 1000 $\mathrm{IU} / \mathrm{ml} \mathrm{LIF}$ and $20 \mathrm{ng} / \mathrm{ml}$ bFGF. The efficiency of PGCcolony formation was evaluated at primary culture.

To determine the period in which PGCs can be obtained by culture, genital ridges were collected from the embryos at 8.5, 9.5, 10.5 and 11.5 dpc. The collected tissues were dispersed and cultured on feeder cells in PGC culture medium supplemented with $1000 \mathrm{IU}$ LIF, $20 \mathrm{ng} / \mathrm{ml} \mathrm{bFGF}$ and $20 \mu \mathrm{M}$ folskolin. The cultured PGCs were passaged at 4- to 7-day intervals. Plates containing colonies and feeder cells were dissociated with $0.04 \%$ (w/v) Trypsin$0.25 \%(\mathrm{w} / \mathrm{v})$ EDTA, centrifuged and seeded onto a fresh feeder layer in a 4-well multidish.

The following experiments to evaluate pluripotency and differentiation properties were performed using cultured PGCs obtained from 9.5 dpc embryos.

Comparison experiments related to the suitable embryonic days for obtaining EG-like colonies or their characterizations were performed using mouse fetuses collected from female mice of the hybrid strain BDF1 (CLEA Japan, Tokyo, Japan) that were mated with male BDF1. Mouse PGCs were cultured under the same conditions as the rabbit PGCs.

\section{Evaluation of alkaline phosphatase (ALP) activity}

PGCs were identified by evaluating the alkaline phosphatase (ALP) activities of cells collected from the genital rodges and cultured cells. For evaluation of the collected cells, digested tissues were spread on a slide glass, air-dried and used for ALP assays. Furthermore, the ALP-assay (ALP histochemistry kit; Sigma-Aldrich) was also performed for undifferentiated EG-like cells. Cultured cells were fixed with $90 \%(\mathrm{v} / \mathrm{v})$ ethanol and used for this assay.

\section{Evaluation of differentiation properties}

To induce differentiation in vitro, EG-like cell colonies were gently dissociated from the plate with the aid of a micropipette and cultured in $10 \%(\mathrm{v} / \mathrm{v})$ FCS-DMEM on a 35-mm non-adhesive petri dish. Embryoid bodies (EB) were maintained in suspension culture, and the medium was changed every other day. After culture for a week, the EBs were plated on gelatin coated dishes and allowed to further differentiate. Differentiation properties were also observed by transplanting the cells into immunodeficient mice (SCID) and inducing teratoma formation. Briefly, approximately 3 $\times 10^{6}$ cultured PGCs were injected into the kidney capsule of an SCID mouse. Twenty days after transplantation, the kidneys were recovered, fixed with neutral formalin and processed with a cryomicrotome. The sections were evaluated following HematoxilinEosin staining.

\section{Immunocytochemistry for characterization of PGCs and differentiated cells}

Cultured PGCs were fixed by $4 \%$ (w/v) paraformaldehyde in PBS (4\% PFA; pH 7.4). For immunocytochemical staining of OCT-4, fixed cells were permiabilized in $0.5 \%$ (v/v) Triton-X (Sigma-Aldrich) diluted in PBS (0.5\% PBT) for 5 min, blocked by incubation in 5\% (w/v) skim milk (Sigma-Aldrich) diluted in PBS for $1 \mathrm{~h}$ and then incubated with the primary antibody overnight at 4 C. The antibodies were anti-OCT-4 rabbit IgG polyclonal antibody (Santa Cruz Biotechnology, Santa Cruz, CA, USA) diluted 1/100 in $0.1 \%(\mathrm{v} / \mathrm{v})$ PBT. For immunostaining of SSEA-1, fixed cells were washed with $0.5 \%(\mathrm{w} / \mathrm{v})$ Bovine serum albumin (BSA) (SigmaAldrich) in PBS (0.5\% BSA) and blocked by incubation in 5\% skim milk for $1 \mathrm{~h}$. The antibody was anti-SSEA-1 mouse monoclonal IgM antibody (Santa Cruz Biotechnology) diluted 1/100 in $0.5 \%$ BSA. For microscopic observation of immunostained samples, sections were incubated for $1 \mathrm{~h}$ at room temperature with Horse radish peroxidase (HRP)-conjugated secondary antibody (all purchased from Santa Cruz Biotechnology) diluted 1/1,000 in $0.1 \%$ PBT or $0.5 \%$ BSA. For evaluation of neural cell differentiation, fixed cells were washed with $0.5 \%$ BSA, blocked with $5 \%$ skim milk for $1 \mathrm{~h}$ and immunized with anti- Neuronal class III $\beta$-tublin mouse monoclonal IgG antibody (TuJ; Abcam, Tokyo, Japan) overnight at $4 \mathrm{C}$. The samples were then observed after reaction with FITC conjugated anti-mouse IgG secondary antibody (Santa Cruz Biotechnology).

RNA isolation, reverse transcription and quantitative PCR

The colonies or EBs were retrieved using a glass capillary pipette and were stored in liquid nitrogen for analysis. Total RNA was extracted using TRIzol (Invitrogen) according to the manufacturer's instructions. Single-strand cDNA was prepared from total RNA using an oligo-dT primer under standard conditions with Superscript III reverse transcriptase (Invitrogen). The cDNA from undifferentiated EG-like colonies were diluted and used for an RTPCR-based assay for Oct4, Sox-2, Vasa, SCP-1, SCP-3 and Gapdh. Differentiation properties were observed by analysis for ectodermal and neural cell marker Nestin, mesodermal marker Desmin and 
endodermal marker Hnf4a (hepatocyte nuclear factor 4a) using cDNA from EBs.

RT-PCR with total cDNA was performed using Platinum Taq PCRx DNA polymerase (Invitrogen) and the following primer sets (listed 5' to 3' in the order of forward and then, reverse primer):

AGTCACTGCTTGATCGTTTG and AAGAACATGTGTAAGCTGCG for Oct-4; AGCATGATGCAGGAGCAG, GGAGTGGGAGGAAGAGGT for Sox-2; CCGTGGAGGATTTGGTCTA, TGTGCAAAGATGGAG-TCCTC for Vasa; ACAGCGAAAAGCCATTCAGG, TCTGGAATTCTCAGCTTGCA for $S c p-1$; TCTAGAATTGTTCAGAGCCAGAG, CAGAATAACATGGATTGAAGAGAC for $S c p$-3; TTTGCAGATGAGGAAGAGAG, ATGCTCTGACTCCTCCAAG for Nestin; AGCAGGAGATGATGGAATAC, TCCAGCAGCTTCCGGTAGG for Desmin; CCTCAAAGCCATCATCTTC, GAAGAGCTTGATGAA-CTGGA for Hnf4a; GGAGCCAAACGGGTCATCATCTC, GAGGGGCCATCCACAGTCTTCT for Gapdh;.

PCR amplifications were performed at $94 \mathrm{C}$ for $2 \mathrm{~min}$ followed by 35 cycles of $94 \mathrm{C}$ for $20 \mathrm{sec}, 56 \mathrm{C}$ for $20 \mathrm{sec}$ and $72 \mathrm{C}$ for $20 \mathrm{sec}$. Reactions were replicated three times.

\section{Statistical analysis}

Statistical analyses of the data were performed with a one-way ANOVA followed by the Tukey-Kramer honestly significant difference (HSD) test for the three sets of results. A P-value of less than 0.05 was considered significant. Statistical analyses were done with a JMP ${ }^{\circledR}$ Statistical Discovery Software (SAS Institute, Cary, NC, USA).

\section{Results}

Growth factor supplementation increased rPGC colonies

We isolated rPGCs from the germinal tissues of rabbit fetuses (Fig. 1). The rPGCs could be maintained under conditions with or without LIF supplementation of the culture medium. The number of rEG-like cell colonies increased with bFGF supplementation. LIF was not indispensable for colony formation, but the co-addition of LIF and bFGF increased the number of colonies (Table 1a). On the other hand, forskolin treatments dramatically affected the expansion and colony formation of rPGCs, increasing by approximately 8 times more than the non-treated controls (Table 1b). Under the conditions of LIF, bFGF and folskolin supplementation, rEG-like colonies were found if the rPGCs were isolated from the embryos at 9.5, 10.5 and $11.5 \mathrm{dpc}$. However, these colonies were not observed when 8.5 dpc embryos were used (Fig. 2).

\section{Expression of pluripotent markers in EG-like colonies formed by $r$ PGCs}

The rPGCs formed colonies resembling mouse EG (mEG) cells in primary culture (i.e., dome-shaped colonies containing cells containing a large nucleus with prominent nucleoli and a relatively small amount of cytoplasm). These cells expressed ALP activity and pluripotent cell markers SSEA-1 and Oct-4 (Fig. 3) in the same manner as mEG cells (Fig. 4). The pluripotency of the cells was also determined by RT-PCR-based analysis (Fig. 5) for Oct-4 and Sox-2. However, most of the colonies were lost prior to completion of four passages, and no teratomas developed in the kidney capsules of the recipient mice that received transplants up to the end of the 20-day experimental period.

In regard to germ cell markers expressed in PGCs, SCP-1 expression was observed, although Vasa and SCP-3 were not detected (Fig. 5). ALP expression rapidly reduced with the differentiation of rEG-like cells.

\section{In vitro differentiation}

When rEG-like cells differentiated in vitro, they rapidly lost the expressions of pluripotent cell markers (data not shown). After approximately 7 days in suspension culture, the rEG-like cells formed simple embryoid bodies (EBs), occasionally containing several cell types, as judged by morphology. RT-PCR analysis revealed that the differentiation markers Desmin, Nestin and $\mathrm{Hnf} 4 \mathrm{a}$ were expressed in the EBs. After adherent culture of the EBs, neuraxis-like structures developed (Fig. 3), and the neural cell marker TuJ was observed (Fig. 3).

\section{Discussion}

In the present study, we isolated, cultured and determined the characteristics of rPGCs in early passage. In mice, it has been

Table 1. Effects of LIF, bFGF and forskolin supplementation on colony formation in primary culture

(a) The number of ALP-positive colonies cultured in bFGF at variable concentrations with or without $\operatorname{LIF}(\mathrm{P}<0.05, \mathrm{n}=3)$

\begin{tabular}{ccccc}
\hline & \multicolumn{5}{c}{$\mathrm{bFGF}(\mathrm{ng} / \mathrm{ml})$} \\
\cline { 2 - 5 } LIF & 0 & 10 & 20 & 30 \\
\hline- & $1.5 \pm 0.5^{\mathrm{a}}$ & $3.5 \pm 1.5^{\mathrm{a}, \mathrm{b}}$ & $3.5 \pm 1.5^{\mathrm{a}, \mathrm{b}}$ & $3 \pm 0^{\mathrm{a}, \mathrm{b}}$ \\
+ & $1.5 \pm 1.5^{\mathrm{a}}$ & $4 \pm 2^{\mathrm{a}, \mathrm{b}}$ & $6 \pm 1^{\mathrm{b}}$ & $6 \pm 1^{\mathrm{b}}$ \\
\hline
\end{tabular}

(b) The number of ALP-positive colonies cultured in the presence of forskolin at 0, 20 and $40 \mu \mathrm{M}$

\begin{tabular}{ccc}
\hline \multicolumn{3}{c}{ Forskolin $(\mu \mathrm{M})$} \\
\hline 0 & 20 & 40 \\
\hline $10.5 \pm 5.5^{\mathrm{a}}$ & $50 \pm 5^{\mathrm{b}}$ & $47 \pm 3^{\mathrm{b}}$
\end{tabular}

The rPGCs were isolated from $9.5 \mathrm{dpc}$ genital ridges and seeded onto mitotically inactivated MEF. The scores are the mean values for three wells of a 4-well multidish $(\mathrm{P}<0.001, \mathrm{n}=4)$. Different superscripts indicate significant differences $(\mathrm{P}<0.05)$. 


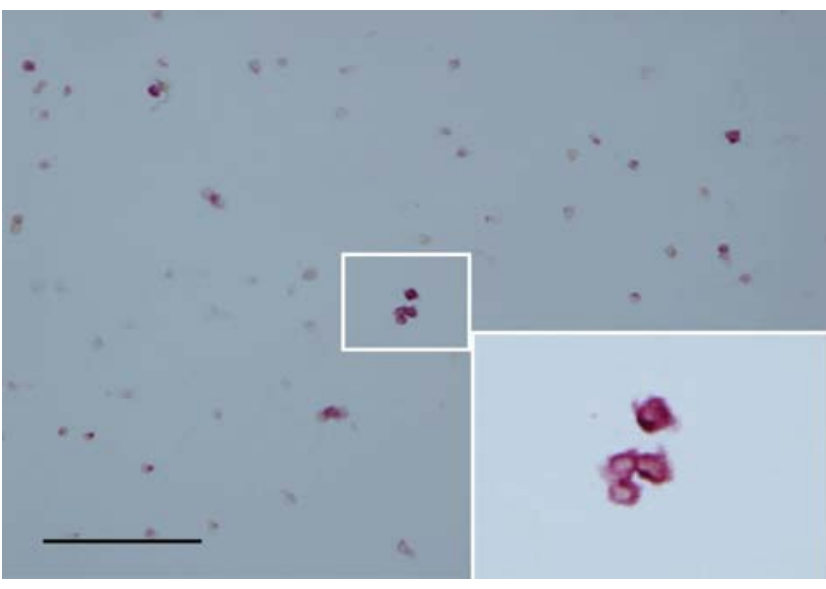

Fig. 1. ALP stained rPGCs in the digested genital ridge of an embryo at 9.5 dpc. Scale bar $=100 \mu \mathrm{m}$.

\begin{tabular}{lcccc} 
A & & & & \\
& $8.5 \mathrm{dpc}$ & $9.5 \mathrm{dpc}$ & $10.5 \mathrm{dpc}$ & $11.5 \mathrm{dpc}$ \\
\hline Mouse & + & + & + & + \\
Rabbit & - & + & + & + \\
\hline
\end{tabular}

\section{B}

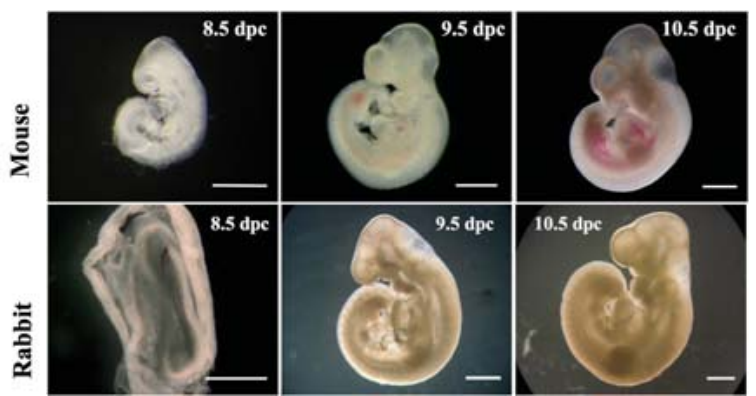

Fig. 2. Establishment of rEG-like cells at various developmental stages. (A) Summary of embryonic days and rEG-like cell foundation after primary culture. (B) Embryos of mice and rabbits on each embryonic day. Scale bars $=1 \mathrm{~mm}$.

reported that co-culture with MEF and addition of LIF and bFGF promotes PGC proliferation and gives rise to EG cells [12]. The hematopoietic cytokine bFGF stimulates stromal and stem cell growth and is a potent mitogenic factor in stimulating cell proliferation of multiple cell types [16]. LIF is a soluble glycoprotein of the interleukin (IL)-6 family of cytokines and is required to maintain pluripotency and permit self-renewal of mouse ES (mES) cells $[17,18]$. Furthermore, it has been reported that supplementation with forskolin also improves cell proliferation. Forskolin is a

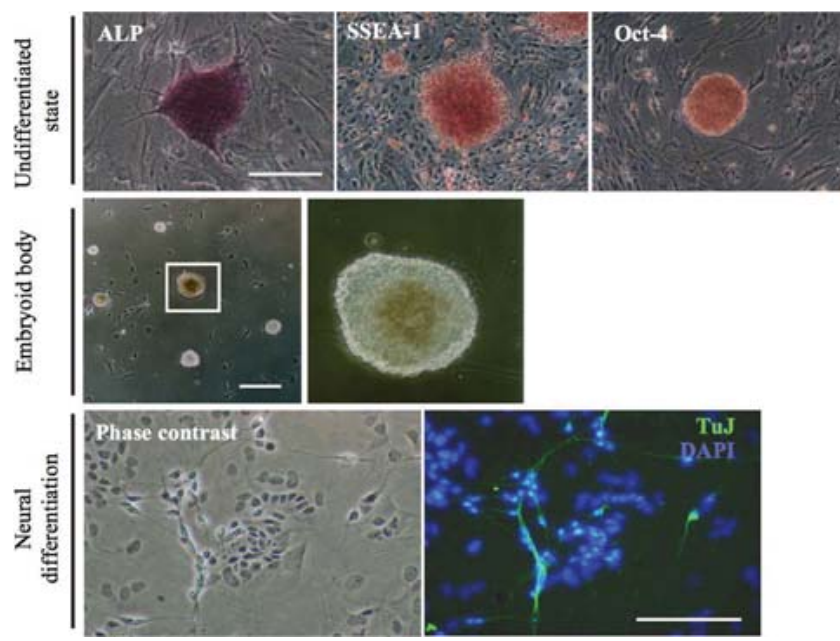

Fig. 3. Characteristics of rEG-like cell colonies. Alkaline phosphatase activity assay (upper left, scale bar=50 $\mu \mathrm{m}$ ). Immunostaining of cell colonies with anti-Oct-4 (upper middle) and anti-SSEA-1 (upper right). The rEG-like cells formed an EB-like structure (middle panel, scale bar $=100 \mu \mathrm{m}$ ). Neural cell differentiation (lower panel). Neuraxis-like structures were immunofluorescently stained using TuJ antibody (scale bar=50 $\mu \mathrm{m}$ ).

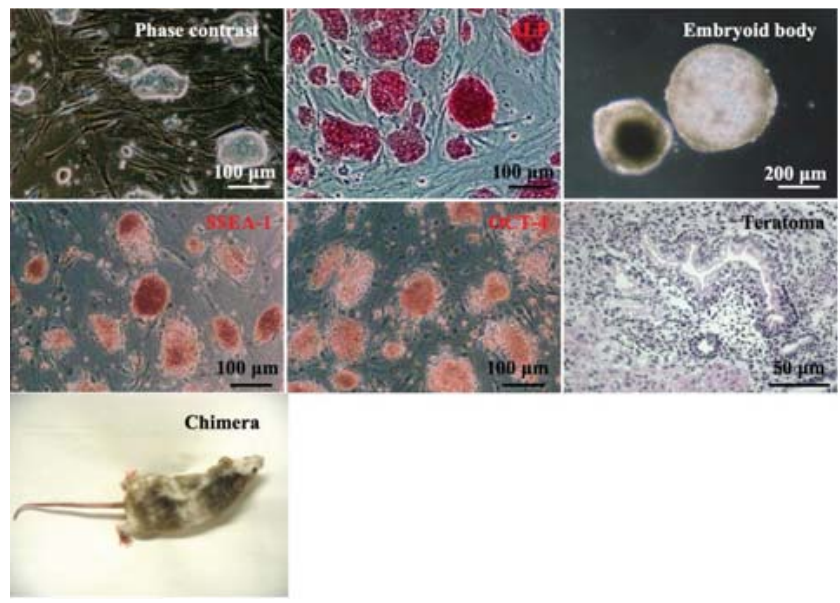

Fig. 4. Pluripotent mouse EG cells. The mEG cells were established as a control using the same culture conditions as for the rEG-like cells. A chimera mouse was obtained by injection of EG cells derived from an 8.5 dpc embryo into an ICR blastocyst.

mediator that enhances intracellular cAMP levels by stimulating adenylate cyclase (protein kinase A), and it has also been reported to significantly promote PGC proliferation $[19,20]$. In the present study, we first demonstrated the synergistic effects of LIF and bFGF and the further effect of forskolin supplementation on rPGC proliferation. Supplementation of LIF improved rPGC survival in culture, and interestingly, bFGF promoted rPGC proliferation and colony formation in a dose-dependent manner only under the LIFadded condition. In addition, a further increase in the number of 


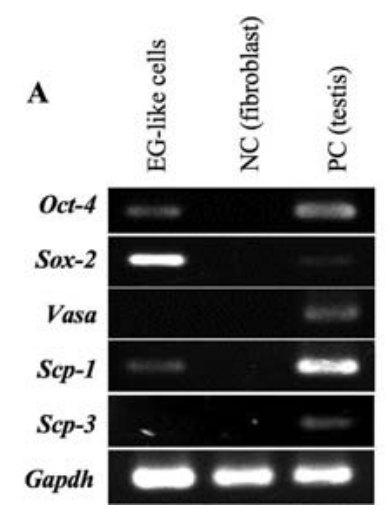

B

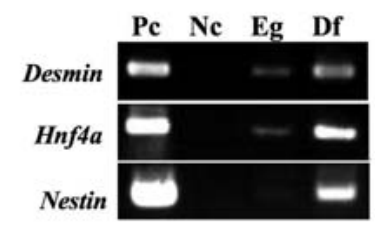

Fig. 5. RT-PCR-based evaluation of lineage specific gene expressions. (A) Examination pf pluripotent cell markers or germ cell-related genes, Oct-4, Sox-2, Vasa, Scp-1 and $S c p-3$. NC=negative control (rabbit dermis-derived fibroblast cells) and $\mathrm{PC}=$ positive control (rabbit testis). (B) Differentiated cell marker expressions were detected in EBs. Mesodermal (Desmin), ectodermal (Nestin) and endodermal (Hnf4a) cell markers were observed. Pc, positive control (fetal heart was used for Desmin, fetal brain was used for Nestin and fetal liver was used for Hnf4a); Nc, negative control (adult lung); Eg, rabbit EG-like cells; Df, differentiated EBs; Br, fetal brain; Ht, fetal heart; Lv, fetal liver; aL, adult lung.

colonies was observed with the combination of the three factors, namely, LIF, bFGF and forskolin (Table 1). It has been reported that bFGF and forskolin activate independent signaling pathways and that they can work additively for mEG cell formation [21]. The rPGCs cultured in the above conditions proliferated on feeder layers and formed dome-shaped colonies in the same manner as mEG cells. These colonies expressed one of the pluripotent cell markers, ALP (Fig. 3).

We also isolated rPGCs from embryos at various developmental stages from 8.5 to 11.5 dpc. The rPGCs could form rEG-like cell colonies when collected from 9.5 to $11.5 \mathrm{dpc}$, but no colonies were observed when we used earlier stage rPGCs (Fig. 2). In mice, pluripotent EG cells could be established from embryos at all stages from 8.5 to 11.5 dpc (Figs. 2 and 4). The mEG cells obtained from early stages such as 7.5 to 8.5 dpc have high pluripotency and germ-line transmission capability [14], and the epigenetic status of these stages resemble mES cells more than later stages [22]. Furthermore, in our experiment, the contributions of mEG cells established from embryos at $8.5 \mathrm{dpc}$ were observed in chimera mice. The developmental schedule of the rabbit is delayed compared with that of the mouse when judged morphologically; in our observations, the $9.5 \mathrm{dpc}$ rabbit fetus resembled the $8.5 \mathrm{dpc}$ mouse fetus (Fig. 2). It is possible that there are very few rPGCs before $9.5 \mathrm{dpc}$, and this might cause the loss of colonies; therefore, we mainly collected rPGCs from 9.5 dpc that morphologically corresponded to $8.5 \mathrm{dpc}$ embryos in mice.

The rEG-like cells established from embryos at $9.5 \mathrm{dpc}$ expressed pluripotent cell markers Oct-4, Sox-2 and SSEA-1 (Figs. 3 and 5); however, the rEG-like cells could not survive past three passages, and they differentiated rapidly or degenerated after seeding without adherence to the feeder layer. These cells could differentiate to embryoid body-like structures, and they expressed differentiation markers. Interestingly, faint expressions of Desmin and Nestin were also detected in rEG-like cells. Desmin and Nestin were early differentiation markers expressed in premature cells; the rEG-like cell cultures were not homogeneous and might have included the cells at various differentiation stages. On the other hand, the endodermal lineage specific gene $\mathrm{Hnf} 4 \mathrm{a}$ was only detected after differentiation. $\mathrm{Hnf} 4 \mathrm{a}$ has been implicated in liver development and hepatocyte differentiation. Furthermore, the EBs produced TuJ-positive neural cells when they attached to the culture dish. Although the rEG-like cells possessed multiple differentiation properties in vitro, they did not form a teratoma when injected into the kidney capsules of SCID mice (data not shown). Based on this restricted proliferation potency and differentiation diversity, we surmised that the cells were not EG cells and that they retained PGC characteristics. Male and female PGCs show cell-autonomous entry into meiosis if they are taken out of the gonadal environment, and it has been reported that PGCs obtained from embryos at $8.5 \mathrm{dpc}$ increase in number for 3 days and then start to decrease on day 4, while proliferation of $11.5 \mathrm{dpc}$ PGCs stops immediately in vitro [22], if they do not develop EG cell characteristics. It has been reported that migrated PGCs express early germinal marker Vasa and meiotic markers such as Scp-1, Scp-3 and Dmc-1 [24-26]. Therefore, we examined the gene expressions of $S c p-1, S c p-3$ and Vasa in rEG-like cells obtained from 9.5 dpc embryos by RT-PCR analysis. Interestingly, no expression of Vasa or $S c p$-3 was detected; only $S c p-1$ expression was observed (Fig. 5). This suggested that the present rEGlike cells might be in an incomplete state of transformation to EG cells. Continuing culture or treatment with other cytokines that induce transformation, such as oncostatin-M, might be effective to obtain more complete cell lines [27].

On the other hand, we may need to consider species-specific characteristics such as vulnerability to enzymatic processing and ability to survive after single cell digestion. It has been reported that the viability of human ES cells is affected by single cell culture due to activation the Rho kinase pathway that induces apoptosis [28]. Alternaively, mES cells can proliferate from single cells. It is possible that rabbit cells might have a pathway that is similar to that in human ES cells and that treatment with a Rho-associated kinase inhibitor might be effective for cell survival.

In summary, we performed rabbit PGC culture and observed the formation of rEG-like colonies. These cells expressed pluripotent markers Oct-4, Sox-2, SSEA-1 and ALP. Furthermore, we demonstrated the synergistic effects of LIF and bFGF and the further effect of forskolin in cell culture; however, these cells possessed restricted differentiation capacity and could not expand past four passages. Although some issues, such as the term of culture, suitable stages of embryos and species-specific characteristics, remain to be clarified, studies using PGCs of various species might give rise to important information related to understanding the mechanisms of mammalian germ cell development.

\section{References}

1. Ohinata Y, Payer B, O'Carroll D, Ancelin K, Ono Y, Sano M, Barton SC, Obukhanych T, Nussenzweig M, Tarakhovsky A, Saitou M, Surani MA. Blimp1 is a critical 
determinant of the germ cell lineage in mice. Nature 2005; 436: 207-213.

2. Ginsberg M, Snow MHL, Mclaren A. Primordial germ cells in the mouse embryo during gastrulation. Development 1990; 110: 521-528.

3. Mintz B, Russell ES. Gene-induced embryological modifications of primordial germ cells in the mouse. J Exp Zool 1957; 134: 207-230.

4. Tam PP, Snow MH. Proliferation and migration of primordial germ cells during compensatory growth in mouse embryos. J Embryol Exp Morphol 1981; 64: 133-147.

5. Durcova-Hills G, Ainscough J, McLaren A. Pluripotential stem cells derived from migrating primordial germ cells. Differentiation 2001; 68: 220- 226

6. Di Carlo AD, Travia G, De Felici M. The meiotic specific synaptonemal complex protein SCP3 is expressed by female and male primordial germ cells of the mouse embryo. Int J Dev Biol 2000; 44: 241-244.

7. Ohkubo Y, Shirayoshi Y, Nakatsuji N. Autonomous regulation of proliferation and growth arrest in mouse primordial germ cells studied by mixed and clonal cultures. Exp Cell Res 1996; 222: 291-297.

8. Farini D, Scaldaferri ML, Iona S, La Sala G, De Felici M. Growth factors sustain primordial germ cell survival, proliferation and entering into meiosis in the absence of somatic cells. Dev Biol 2005; 285: 49-56.

9. Pesce M, De Felici M. Apoptosis in mouse primordial germ cells: a study by transmission and scanning electron microscope. Anat Embryol (Berl) 1994; 189: 435-440.

10. Matsui Y, Toksoz D, Nishikawa S, Nisihikawa S, Williams D, Zsebo K, Hogan BL. Effect of steel factor and leukaemia inhibitory factor on mursine primordial germ cells in culture. Nature 1991; 353: 750-752.

11. Dolci S, Williams DE, Ernst MK, Resnick JL, Brannan CI, Lock LF, Lyman SD, Boswell HS, Donovan PJ. Requirement for mast cell growth factor for primordial germ cell survival in culture. Nature 1991; 352: 809-811.

12. Matsui Y, Zsebo K, Hogan BL. Derivation of pluripotential embryonic stem cells from murine primordial germ cells in cultute. Cell 1992; 70: 841-847.

13. Resnick JL, Bixler LS, Cheng L, Donovan PJ. Long-term proliferation of mouse primordial germ cells in culture. Nature 1992; 359: 550-551.

14. Labosky PA, Barlow DP, Hogan BL. Mouse embryonic germ (EG) cell lines: transmission through the germline and differences in the methylation imprint of insulin-like growth factor 2 receptor (Igf2r) gene compared with embryonic stem (ES) cell lines. Development 1994; 120: 3197-3204

15. Shamblott MJ, Axelman J, Wang S, Bugg EM, Littlefield JW, Donovan PJ, Blumenthal PD, Huggins GR, Gearhart JD. Derivation of pluripotent stem cells from cultured human primotdial germ cell. Proc Natl Acad Sci USA 1998; 95: 13726-13731.

16. Bögler O, Wren D, Barnett SC, Land H, Noble M. Cooperation between two growth factors promotes extended self-renewal and inhibits differentiation of oligodendro- cyte-type-2 astrocyte(O-2A) progenitor cells. Proc Matl Acad Sci USA 1990; 87: 63686372.

17. Smith AG, Heath JK, Donaldson DD, Wong GG, Moreau J, Stahl M, Rogers D. Inhibition of pluripotential embryonic stem cell differentiation by purified polypeptides. Nature 1988; 336: 688-690

18. Williams RL, Hilton DJ, Pease S, Willson TA, Stewart CL, Gearing DP, Wagner EF, Metcalf D, Nicola NA, Gough NM. Myeloid leukaemia inhibitory factor maintain the developmental potential of embryonic stem cells. Nature 1998; 15: 336-337.

19. De Felici M, Dolci S, Pesce M. Proliferation of mouse primordial germ cells in vitro: a key role for cAMP. Dev Biol 1993; 157: 277-280.

20. Dolci S, Pesce M, De Felici M. Combined action of stem cell factor, leukemia inhibitory factor, and cAMP on in vitro proliferation of mouse primordial germ cells. Mo Reprod Dev 1993; 35: 134-139.

21. Koshimizu U, Taga T, Watanabe M, Saito M, Shirayoshi Y, Kishimoto T, Nakatsuji $\mathbf{N}$. Functional requirement of gp130-mediated signaling for growth and survival of mouse primordial germ cells in vitro and derivation of embryonic germ (EG) cells. Development 1996; 122: 1235-1242.

22. Sato S, Yoshimizu T, Sato E, Matsui Y. Erasure of methylation imprinting of Igf2r during mouse primordial germ-cell development. Mol Reprod Dev 2003; 65: 41-50.

23. Ohkubo Y, Shirayoshi Y, Nakatsuji N. Autonomous regulation of proliferation and growth arrest in mouse primordial germ cells studied by mixed and clonal cultures. Exp Cell Res 1996; 222: 291-297.

24. Toyooka Y, Tsunekawa N, Takahashi Y, Matsui Y, Satoh M, Noce T. Expression and intracellular localization of mouse Vasa-homologue protein during germ cell development. Mech Dev 2000; 93: 139-149.

25. Dobson MJ, Pearlman RE, Karaiskakis A, Spyropoulos B, Moens PB. Synaptonemal complex proteins: occurrence, epitope mapping and chromosome disjunction. $\mathrm{J} \mathrm{Cell}$ Sci 1994; 107: 2749-2760.

26. Yoshida K, Kondoh G, Matsuda Y, Habu T, Nishimune Y, Morita T. The mouse RecA-like gene $\mathrm{dmc} 1$ is required for homologous chromosome synapsis during meiosis. Mol Cell 1998; 1: 707-718.

27. Hara T, Tamura K, de Miguel MP, Mukouyama Y, Kim H, Kogo H, Donovan PJ Miyajima A. Distinct roles of oncostatin $\mathrm{M}$ and leukemia inhibitory factor in the development of primordial germ cells and Sertoli cells in mice. Dev Biol 1998; 201: 144 153.

28. Watanabe K, Ueno M, Kamiya D, Nishiyama A, Matsumura M, Wataya T, Takahashi JB, Nishikawa S, Nishikawa S, Muguruma K, Sasai Y. A ROCK inhibitor permits survival of dissociated human embryonic stem cells. Nat Biotechnol 2007; 25: 681686 